\title{
Immunohistochemical and molecular analyses of HER2 status in breast cancers are highly concordant and complementary
} approaches

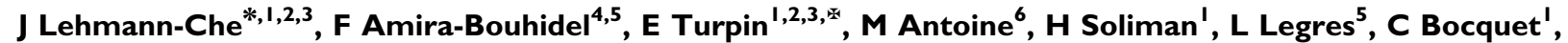 \\ R Bernoud $^{5}$, E Flandre ${ }^{6}$, M Varna $^{5}$, A de Roquancourt ${ }^{3,4,5}$, L-F Plassa', S Giacchetti ${ }^{7}$, M Espié ${ }^{7}$, C de Bazelaire ${ }^{8}$,

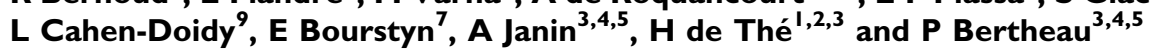 \\ 'AP-HP, Hosp Saint-Louis, Department of Biochemistry, Paris 75010 , France; ${ }^{2}$ CNRS UMR72I 2/INSERMU944, Paris 75010 , France; ${ }^{3}$ Univ Paris \\ Diderot, Sorbonne Paris Cité, Paris 750 I 0, France; ${ }^{4}$ AP-HP. Hosp Saint-Louis, Department of Pathology, Paris 750 I 0, France; ${ }^{5}$ INSERM UMR_S728, Paris \\ 750 10, France; ${ }^{6}$ AP-HP, Hosp Tenon, Department of Pathology, Paris 750 I 0, France; ${ }^{7}$ AP-HP, Hosp Saint-Louis, Breast Diseases Center, Paris 75010 , \\ France; ${ }^{8}$ AP-HP, Hosp Saint-Louis, Department of Radiology, Paris 75010 , France; ${ }^{9}$ AP-HP, Hosp Saint-Louis, Department of Surgery, Paris 75010 , France
}

BACKGROUND: Immunohistochemistry (IHC) and fluorescent in situ hybridisation (FISH) are currently the most commonly used methods to assess HER2 status. PCR-based assays allow quantitative determination of HER2 amplification (Q-PCR) or overexpression (Q-RT-PCR), but are not routinely used. We evaluated the relevance of Q-RT-PCR for HER2 status determination.

METHODS: We compared IHC and Q-RT-PCR in 466 breast tumours. In discordant or equivocal cases, five additional methods (IHC with two other antibodies, FISH, silver in situ hybridisation (SISH) and Q-PCR) were combined to determine HER2 status. Two cases with HER2 intra-tumour heterogeneity were further explored by allelic profiles analysis and HUMARA clonality determination after microdissection.

RESULTS: We observed 97.3\% concordance between Q-RT-PCR and non-equivocal IHC. Twelve out of 466 cases (3\%) revealed discordances between the two methods. The power of Q-RT-PCR to predict HER2 status (defined by seven methods) was similar to that of IHC. Although rare, some discordances between techniques might be due to HER2 intra-tumour heterogeneity and we report two examples, one tumour containing two distinct clones, another tumour consisting of HER2 amplified and non-amplified subclones.

CONCLUSION: Q-RT-PCR and IHC are highly concordant methods for HER2 status assessment, and Q-RT-PCR allows a highly reliable quantitative assessment and could be a useful adjunct to $\mathrm{HC}$.

British Journal of Cancer (201I) 104, 1739-1746. doi:I0.1038/bjc.2011.135 www.bjcancer.com

Published online 3 May 2011

(c) 20II Cancer Research UK

Keywords: HER2; HER2/neu; ERBB2; c-erb-b2; heterogeneity; real-time PCR

The HER2 gene encodes the human epidermal growth factor receptor 2 with tyrosine kinase activity (Slamon et al, 1987) and is overexpressed in 15-20\% of breast cancers (Owens et al, 2004), through gene amplification with well correlated level of protein expression (Pauletti et al, 1996; Yarden, 2001). This molecular abnormality defines breast tumours with poor prognosis and increased risk of early relapse (Slamon et al, 1987, 1989), but predicts response to the humanised monoclonal anti-HER2 antibody trastuzumab (Herceptin) or to small tyrosine kinase inhibitors such as lapatinib or erlotinib.

The increasing number of patients with breast cancer whose survival has been improved by trastuzumab treatment underlines the need for sensitive, specific, highly reproducible and

\footnotetext{
*Correspondence: Dr J Lehmann-Che;

E-mail: jacqueline.lehmann-che@sls.aphp.fr

Deceased.

Received 4 January 2011; revised 18 March 2011; accepted 28 March 20I I; published online 3 May 20 I I
}

cost-efficient methods to identify patients eligible for anti-HER2 therapies. Furthermore, HER2 status not only predicts anti-HER2 efficacy, but could also determine other treatment options. Indeed, HER2-overexpressing breast tumours are often resistant to hormonotherapy and more sensitive to anthracycline-based and taxane-containing chemotherapy (Paik et al, 2000; Pritchard et al, 2008), so that all invasive breast cancer need an HER2 evaluation at diagnosis.

In daily practice, according to the American Society of Clinical Oncology/College of American Pathologists (ASCO/CAPs) recommandations (Wolff et al, 2007), HER2 status is determined by immunohistochemistry (IHC) followed, if necessary, by fluorescent in situ hybridisation (FISH), although FISH first-line determination is also encouraged by some authors (Sauter et al, 2009). Immunohistochemistry results are obtained on formalinfixed paraffin-embedded (FFPE) samples and expressed as a fourscale score system ( 0 to $3+)$. Determination of HER2 status by FISH is also performed on FFPE samples. It shows the mean number of HER2 copies using a DNA probe hybridising to the 
HER2 gene alone or in association with a centromeric probe as control for chromosome 17 copy number expressed as HER2/ CEN17 ratio. Fluorescent in situ hybridisation is now challenged by chromogenic (CISH) or silver in situ hybridisation (SISH), faster methods using a chromogenic signal that do not decay over time, that can be further reevaluated and need only a classical light microscope (Isola et al, 2004; Laakso et al, 2006; Papouchado et al, 2010). A 'gold standard' for HER2 determination does not really exist and the ASCO/CAPs study estimates that $20 \%$ of current HER2 tests may be inaccurate owing to multiple preanalytic and analytic variables (Wolff et al, 2007). Indeed, the existence of various IHC protocols, FDA-approved antibodies or probes contributes to interlaboratory variability. Improvement in HER2testing reproducibility between laboratories is crucial and new HER2-testing technologies are also needed.

Different studies have evaluated the performance of Q-RT - PCR or Q-PCR to determine the HER2 status (Laudadio et al, 2007). Quantitative PCR using primers flanking the HER2 gene or mRNA can quantify gene amplification or messenger overexpression. PCR-based assays are easy, rapid, sensitive, specific and quantitative approaches without the inherent inter-observer variability of IHC and FISH/CISH techniques. It can be used on small samples and can be standardised and automated. DNA extraction can also be performed on FFPE tissues. However, RT-PCR technology, more sensitive to RNA quality, is more robust if frozen tissues are used. The main PCR drawback is that DNA or RNA extraction mixes tumour and non-tumour cells and can lead to tumour cells dilution with risk of false negative. Conversely, the mix of invasive tumour cells with high-grade intraductal HER2-positive tumour cells can lead to false positive results. Provided that sample purity is controlled with microscopical examination, PCR-based determination has been shown to correlate well with IHC and FISH (Vinatzer et al, 2005; Barberis et al, 2008).

In order to evaluate the benefits of PCR-based technology in daily HER 2 testing, we performed a large prospective study comparing HER2 determination with IHC and Q-RT-PCR. As recommended in guidelines, IHC $2+$ cases were further explored not only by FISH and SISH but also by other IHC tests and Q-PCR. Moreover, all discordant cases were explored by these additional techniques. We also analysed extensively two cases showing striking HER2 intra-tumour heterogenity that may explain some technical discordances.

We observed that molecular approaches are powerful and reliable quantitative tools for HER2 status assessment that could complement IHC for optimal patient care.

\section{MATERIALS AND METHODS}

\section{Patients and samples}

We analysed 466 primary breast tumours obtained from patients treated in Saint Louis Hospital (Paris) from 2002 to 2007. All patients were informed of the study according to our Institutional Review Board recommendations. A total of 332 samples were obtained from surgical specimen and 134 were obtained with fine-needle biopsies. Tumours with $>10 \%$ in situ component were excluded from this study. Haematoxylin-eosin (H\&E) stainings, immunohistochemical stainings and in situ hybridisation techniques were performed on FFPE tissue samples. Q-RT-PCR and Q-PCR were performed on RNA and DNA extracted from frozen tissues.

\section{IHC detection}

HER2 immunohistochemistry was performed with the monoclonal HER2 CB11 antibody (Novocastra, Newcastle upon Tyne, UK, dilution 1/250) in the BenchmarkXT immunostainer (Roche Diagnostics, Basel, Switzerland) with calibrated positive controls and internal (on slide) negative controls. Evaluation of immunostainings was performed by two pathologists (PB, AR) and scored according to ASCO guidelines (Wolff et al, 2007; Gown, 2008): negative for 0 (no membrane staining) and $1+$ (faint or barely perceptible incomplete membrane staining); equivocal for $2+$ (10-30\% tumour cells with strong complete membrane staining or $>10 \%$ tumour cells with moderate complete membrane staining) and positive for $3+(>30 \%$ tumour cells with strong complete membrane staining).

For discordant and CB11 equivocal cases, HER2 immunohistochemistry was performed with A0485 polyclonal (Dako, Glostrup, Denmark, dilution 1/500) and 4B5 monoclonal antibody (Roche Diagnostics, prediluted) using the Discovery immunostainer (Roche Diagnostics). HER2 scores were evaluated as described below.

Other antibodies were used with the Discovery immunostainer: oestrogen receptor (Novocastra, clone 6F11, dilution 1/50), progesteron receptor (Novocastra, clone 312, dilution 1/75), cytokeratin 5/6 (Dako, clone B4, dilution 1/50), cytokeratin 17 (Dako, clone E30, dilution 1/50) and cytokeratin 8 (Millipore, Billerica, MA, USA, clone MAB 3414, 1/50).

\section{SISH and FISH detection}

Silver in situ hybridisation and FISH were performed on $3 \mu \mathrm{m}$ paraffin tissue sections. Silver in situ hybridisation staining, with HER2 and chromosome 17 probes, was performed in BenchmarkXT slide stainers (Roche Diagnostics) and described in Dietel et al (2007). Fluorescent in situ hybridisation staining was performed using the Zytolight Spec HER2/CEN17 kit (Zytovision, CliniScience, Montrouge, France) according to the manufacturer's protocol. Fluorescence signal were counted by one pathologist (MA) using a (Leica DM 4000) Zeiss Axioscope Imager Z1 fluorescence microscope (Zeiss, Oberkochen, Germany). A minimum of 80 tumour cell nuclei, with intact morphology according to DAPI counterstaining, were counted. The HER2/CEN17 ratio was obtained by dividing the mean number of HER2 signals by the mean number of CEN17 signals in tumour cells and defined HER2 gene amplification if $>2.2$, equivocal if between 1.8 and 2.2 and no HER2 amplification if $<1.8$, according to ASCO/CAPs recommendations (Wolff et al, 2007).

\section{Quantification of HER2 overexpression by Q-RT - PCR and HER2 gene copy number by Q-PCR}

Nucleic acids were extracted by phenol/chloroform procedure. Tumour cell purity and presence of in situ carcinoma were assessed on adjacent H\&E-stained sections. Quantitative PCR were performed on LightCycler 2.1 instrument (Roche Diagnostics). HER2 overexpression was evaluated by relative quantification using TATA-binding protein as endogen control (Bossard et al, 2005). Final result was expressed as a normalised ratio considered as over-expressed if $>7$. The cut-off ratio was determined on a tumours training set using univariate partition method (XLSTAT software) and correlation with IHC-HER2 expression. HER2 amplification was evaluated on DNA using the LightCycler-HER-2/neu DNA Quantification kit (Roche Diagnostics) in all $\mathrm{IHC} 2+$ and IHC/Q-RT-PCR discordant specimens. The assay amplifies simultaneously one HER2 fragment and one gastrin fragment, the reference gene localised on the chromosome 17. Results were expressed as the ratio of HER2/gastrin in the sample, normalised with the same ratio in the calibrator DNA set. A ratio above 2 was considered amplified. Results between 2 and 3 were repeated.

\section{Allelic profiles analysis}

Allelic profiles were analysed as described in Varna et al (2007). We used a PALM Microbeam/Olympus system to perform laser tissue microdissection on FFPE tissue sections. PCR was performed directly on cell lysates with at least 500 cells for each 
PCR. Five microsatellite dinucleotide repeats were used: D17S250, D17S855, D17S1840, D13S153 and D9S171. Whole tumour allelic profiles and microdissected areas allelic profiles were compared.

\section{Clonality assessment using androgen receptor gene methylation pattern}

The androgen receptor gene (HUMARA) polymorphism is characterised by highly polymorphic short-tandem CAG repeat units, $100 \mathrm{bp}$ downstream of a methylated site in the coding region of its first exon (Lucas et al, 1997; Fujita et al, 1998; Wang et al, 2007). Before digesting the genomic DNA with methylationsensitive restriction enzyme HpaII, electrophoresis of heterozygote cases shows two alleles. After digesting the genomic DNA with HpaII, electrophoresis shows two different alleles if the tumour is not monoclonal and only one allele or at least strong allelic imbalance if the tumour is of monoclonal origin due to $\mathrm{X}$-chromosome inactivation mosaicism, as solely the inactive methylated allele is not cut at the restriction site and hence PCR amplified.

Tumour DNA was amplified at the HUMARA locus either with or without HpaII predigestion and overall tumour profiles and microdissected areas profiles were compared.

\section{RESULTS}

\section{IHC and Q-RT - PCR comparisons}

To determine HER2 status, we performed immunohistochemistry with CB11 antibody and Q-RT-PCR on all 466 cases (Figure 1). Overall concordance was excellent (97.3\%), especially in IHC $0,1+$ subgroup (348 negative Q-RT-PCR/351 IHC 0/1+: 99.2\%). Concordance was also good in IHC $3+$ cases ( $91 \%$ : 92 positive Q-RT-PCR/101 IHC $3+$ ). However, in 12 out of 466 cases (3\%), the two techniques were discordant (either IHC $0,1+/ \mathrm{Q}-\mathrm{RT}-$ PCR $>7$ or IHC $3+/ \mathrm{Q}-\mathrm{RT}-\mathrm{PCR}<7$ ). Among these 12 discordant cases, 11 had been obtained after surgical procedure and only one after fine-needle biopsy. In the 14 out of 466 IHC $2+$ equivocal cases, Q-RT - PCR showed the absence of HER2 overexpression in 13 out of 14 cases $(93 \%)$.

\section{Analysis of the $\mathbf{2 6}$ discordant or equivocal cases}

According to guidelines, all IHC score $2+(n=14)$ were analysed not only by hybridisation methods (FISH and SISH), but also with two other IHC-HER2 antibodies and Q-PCR (Figure 2). These additional methods were also performed in all discordant cases $(n=12)$. An overall HER2 status was defined for each of these 26 discordant or equivocal cases, based on the results of all seven techniques used, a case being HER2 positive if there were more positive than negative results ( 12 out of 26 cases), being negative if there were more negative than positive results (12 out of 26 cases) and being HER 2 unclassified in other situations (2 out of 26 cases). Among the 14 equivocal cases, 4 were finally scored positive by the overall HER2 status, 9 negative and 1 remained undefined. In these equivocal cases, Q-RT-PCR analysis predicted the final HER2 status in 10 cases and failed in only 3 cases. However, in the 12 discordant cases, Q-RT-PCR predicted final HER2 status in only two cases and failed in nine cases.

The overall ability of Q-RT - PCR to predict final HER2 status in the 24 cases with known final HER2 status was, therefore, 12 out of 24, while the overall ability of IHC CB11 to predict final HER2 status was 9 out of 24 . Accordingly, Q-RT-PCR and IHC, respectively, predicted the overall HER2 status in 452 tumours and in 449 tumours. Among the 26 IHC/Q-RT - PCR discordant or IHC $2+$ cases, only six tumours (\#1, 2, 14, 23, 24 and 25) showed highly concordant results, with 6 out of 7 methods showing similar results. The other 20 cases all showed more extensive discrepancies among the techniques used, with only three to five concordant methods. The results in case \#4, either positive or borderline, were possibly due to chromosome 17 polysomy that was demonstrated with FISH and SISH techniques. In case \#17 (Figure 2B), we observed heterogeneous IHC staining among the three antibodies used, as well as FISH negativity and moderate amplification with SISH. In the other cases, no easy explanation could be given for these technical discrepancies and either borderline HER2 status or true intra-tumour heterogeneity could be implicated.

\section{Phenotype and genotype analyses of two cases with HER2 intra-tumour heterogeneity}

In order to explore one possible cause of discordances between techniques, we analysed two cases that showed obvious intratumour HER2 heterogeneity.

In Case A, H\&E examination showed the presence of a 1-cm less differentiated area (area 1) located inside the main tumour component (area 2) (Figure 3A). Area 1 was scored $3+$ for HER2, was positive for CK5/6 and negative for ER, PR, CK8 and CK17, while area 2 was negative for HER2, CK5/6 and CK17 and positive for ER, PR and CK8. Silver in situ hybridisation confirmed HER2 amplification only in tumour cells of area 1 (Figure 3A).
A

\begin{tabular}{|c|cc|c|}
\hline $\begin{array}{c}\text { IHC } \\
(\text { CB11 })\end{array}$ & RNA negative & $\begin{array}{c}\text { RNA } \\
\text { positive } \\
(>7)\end{array}$ & $\begin{array}{c}\text { Patients } \\
\text { number }\end{array}$ \\
\hline $0,1+$ & 348 & 3 & 351 \\
$2+$ & 13 & 1 & 14 \\
$3+$ & 9 & 92 & 101 \\
\hline $\begin{array}{c}\text { Patients } \\
\text { number }\end{array}$ & 370 & 96 & 466 \\
\hline
\end{tabular}

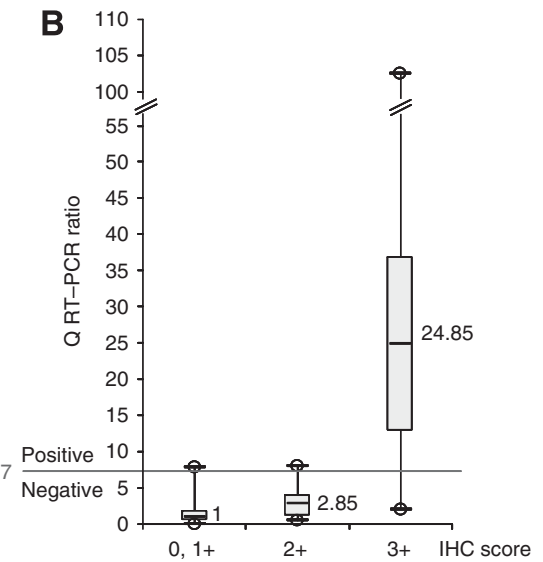

Figure I Comparison of HER2 determination by IHC (CBII) and Q-RT-PCR on 466 breast tumours treated in St Louis Hospital. (A) Distribution of tumour samples according to HER2 status assessed on formalin-fixed, paraffin-embedded samples with $0 / I+, 2+$ and $3+$ IHC scores and Q-RT-PCR on fresh frozen samples, with a cut-off ratio of 7. (B) HER2 Q-RT-PCR ratio according to the three IHC score groups: each box shows the 25-75th percentile (box extremities), the median values (line in the box and value outside) and the lowest and highest values (bottom and top bars of the whisker). 
A
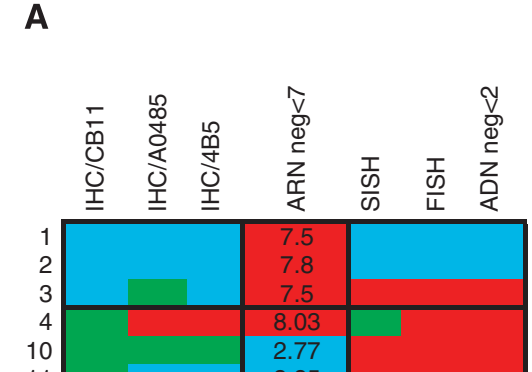

There was allelic loss at D17S855 in area 1 but not in area 2 (data not shown). Allelic profiles with the other microsatellites were either non-informative or showed no significant difference between the two areas (data not shown). The analysis of the $\mathrm{X}$-chromosome methylation pattern showed important differences between areas 1 and 2 (Figure 3B): before HpaII digestion, allelic profiles showed LOH in each area, but on two distinct alleles. After HpaII digestion, profiles showed inactivation of one X chromosome in both areas 1 and 2, indicating that both areas are populated by monoclonal cells. However, areas 1 and 2 did not inactivate the same $\mathrm{X}$ chromosome, demonstrating that they are not deriving from the same clone.

In Case B (case \#18 of this study), HER2 immunohistochemical staining (Figure 4A) showed two sharply demarcated areas, one with a strong membranous staining in over $80 \%$ of tumour cells (area 1) and one totally negative (area 2). These two areas looked totally similar on $\mathrm{H} \& \mathrm{E}$ staining. Other immunostainings (ER, PR, CK5/6, CK17 and CK8) were similar in both areas (data not shown). Silver in situ hybridisation confirmed HER2 amplification in area 1 and lack of amplification in area 2, with sharp borders between the two areas (Figure 4A). Allelic profiles obtained after microdissection with D17S1840 showed only one allele in area 1 and only the other allele in area 2, consistent with subclonal heterogeneity (Figure 4B). For D17S250, one new allele was observed in the non-microdissected tumour, as well as in areas 1 and 2 (Figure 4B), strongly suggesting that areas 1 and 2 are derived from a common tumour cell. Allelic profiles with the three other microsatellites were almost similar in both areas. The analysis of the X-chromosome methylation pattern was not informative since it showed inactivation of the same $\mathrm{X}$ chromosome in both areas (data not shown).

\section{DISCUSSION}

Selection of patients for trastuzumab treatment is primarily performed by IHC using HercepTest, CB11 or 4B5 antibody, as recommended (Birner et al, 2001; Wolff et al, 2007). HER2 immunostaining is easy to perform, available as a standard method in pathology laboratories, widely applicable (on FFPE specimens), very reliable (Lebeau et al, 2010; Purdie et al, 2010) and relatively inexpensive, but is only a semi-quantitative method. Yet, in $3-15 \%$ of cases (Dendukuri et al, 2007), IHC is equivocal and further analyses are required, leading to the usual IHC + FISH association. Like IHC, FISH is a semi-quantitative morphological method but with higher costs and need of specialised expertise and equipment. In the context of HER2 status assessment, Q-RT-PCR could also be a useful option and an alternative to the current IHC + FISH procedure. Several studies have already compared IHC and Q-RT-PCR (Cronin et al, 2004; Ginestier et al, 2004; Gjerdrum et al, 2004; Bossard et al, 2005; Esteva et al, 2005; Vanden Bempt et al, 2005; Vinatzer et al, 2005; Bergqvist et al, 2007; Kostopoulou et al, 2007; Barberis et al, 2008; Cuadros et al, 2010) (Table 1). These reports showed good overall concordance $(82-100 \%)$ with frozen or FFPE specimen, and mostly without microdissection, but in small patient series. Moreover, HER2 mRNA evaluation was shown to be a fast, reliable and cost-effective alternative to the IHC + FISH procedure and also correlated with overall survival and disease-free survival (Vinatzer et al, 2005). 
A

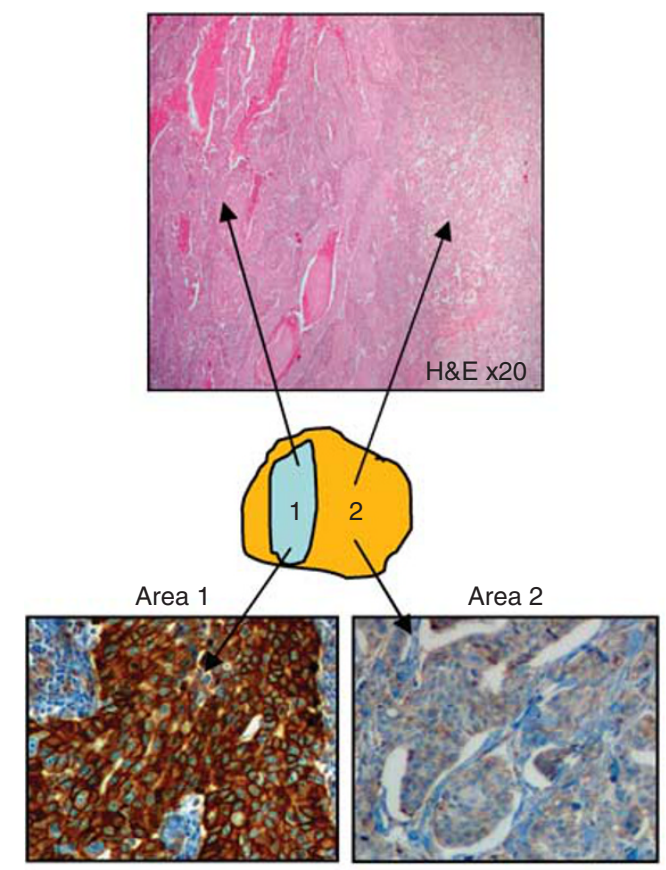

B

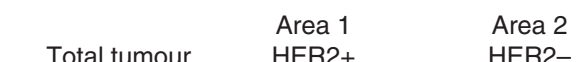

HER2
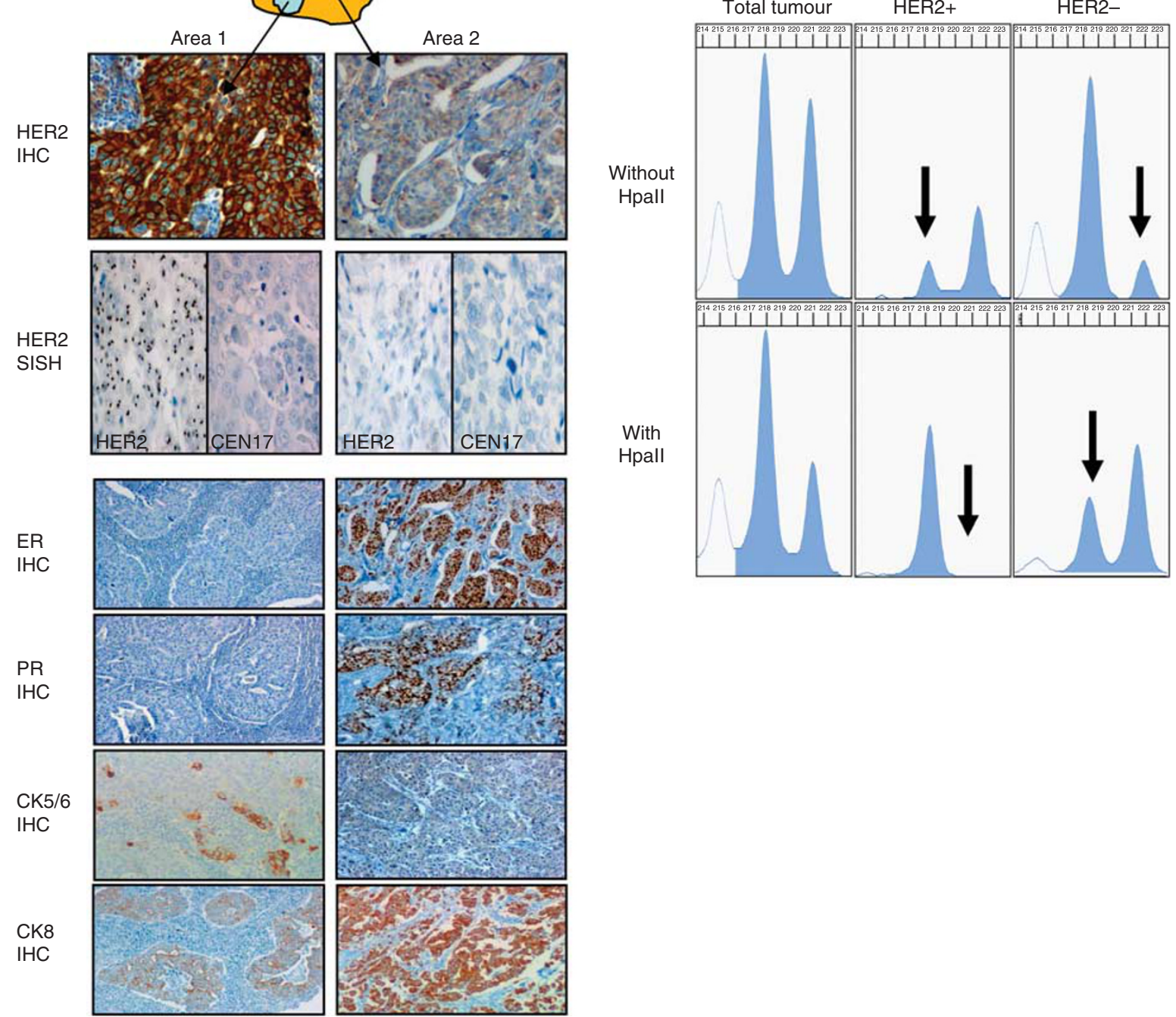

Figure 3 Analysis of case A heterogeneity. (A) Schematic representation of case A with distinction of area I (HER2 + ) and area 2 (HER2-): H\&E section, immunohistochemical stainings for HER2, ER, PR, CK5/6, CK8 and SISH evaluation of HER2 (magnification $\times 250$ ). (B) Analysis of X-chromosome methylation pattern (HUMARA): allelic profiles for the total tumour and microdissected areas I and 2 are shown, before Hpall (upper line) and after Hpall (lower line) digestion. Differences between the two areas are represented by arrows.

In this prospective study of 466 breast tumours comparing IHC and Q-RT-PCR determination of HER2 status, we show that Q-RT-PCR was very strongly correlated with IHC (overall concordance $97.3 \%$ ). In the 12 discordant cases, Q-RT-PCR was not as powerful as IHC to predict the final HER2 status determined by five other methods, with seven and one false negative cases and two and one false positive cases for Q-RT-PCR and IHC, respectively. However, four cases (Figure 2A, cases \#23, 24, 25 and 26) among the seven Q-RT-PCR false negative cases had ratios very close to the cut-off value, suggesting that tumour cells dilution could explain the discrepancy. Note that in cases \#23, 24 and 25, only Q-RT-PCR method was unable to predict the HER2 positivity, perhaps because mRNA analysis can be tricky in borderline cases. Similarly, in the two false positive cases (\#1 and \#2), the ratio was also close over the cut-off value and \#1 presented a small in situ component, although evaluated to be $<10 \%$. 
A

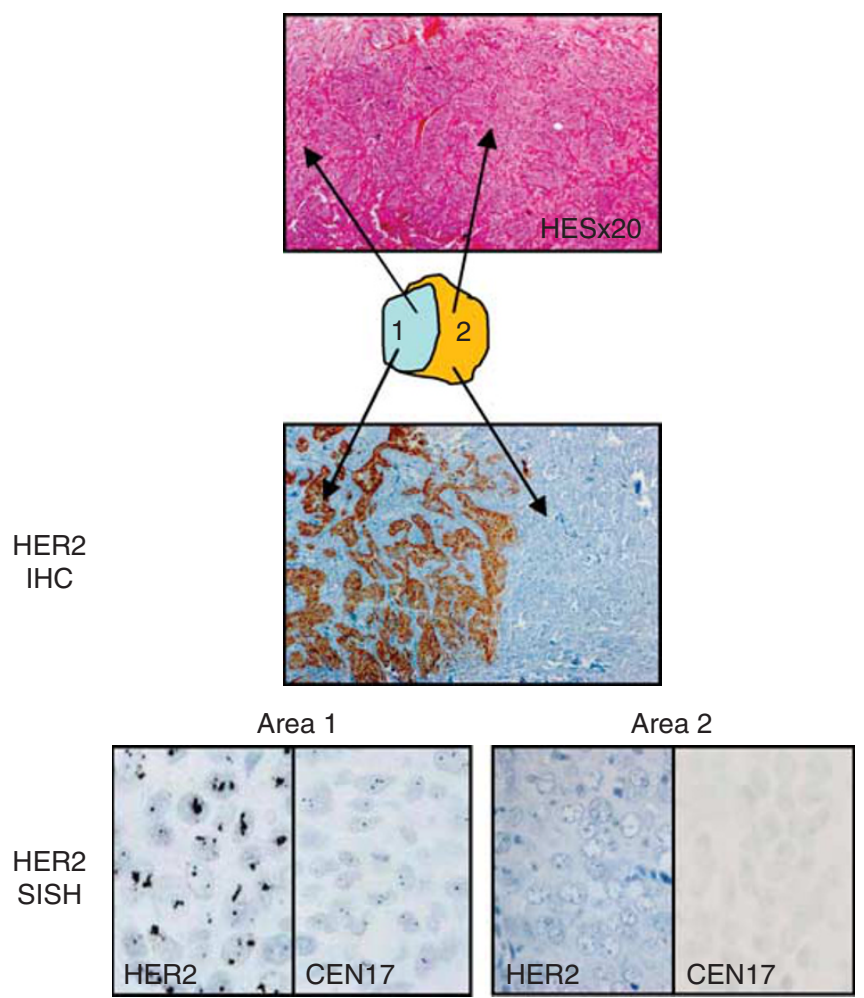

D17S1840

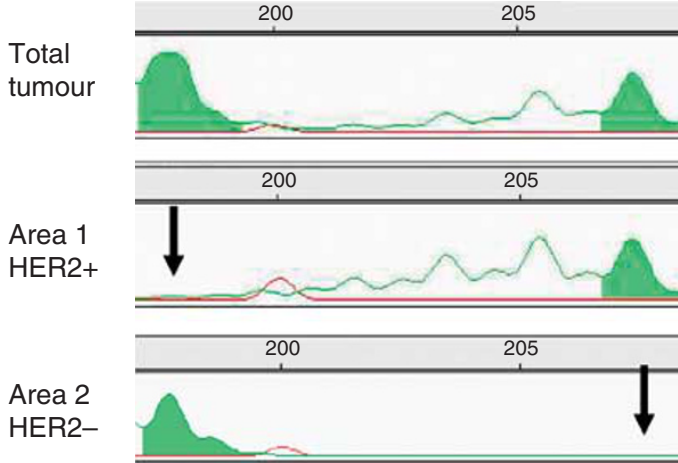

D17S250

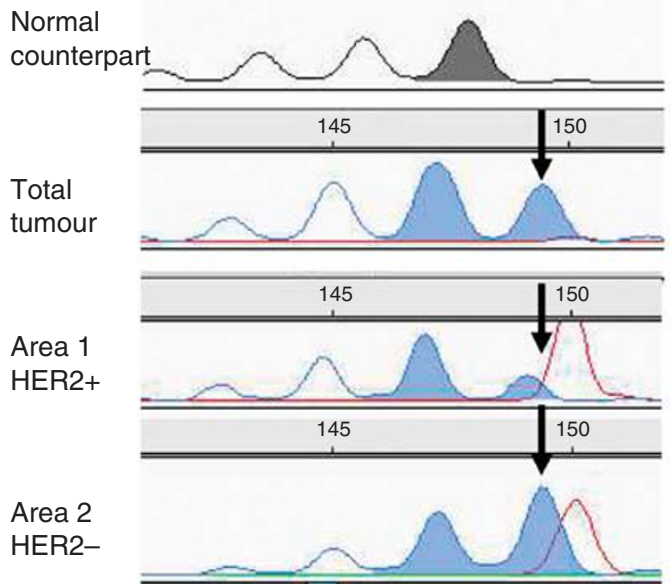

Figure 4 Analysis of case B heterogeneity. (A) Schematic representation of case B with distinction of areas I and 2: in H\&E section, in immunohistochemical stainings for HER2 and SISH evaluation of HER2 (magnification $\times 250$ ). (B) Analysis of allelic profile using DI7SI840 and DI7S250 microsatellites after microdissection of areas I and 2. The profile in grey represents the normal counterpart and the profile in green or blue the different tumour areas and the total tumour before microdissection. The arrows point to loss of heterozygosity (DI7SI840) or to new alleles (DI7S250).

More importantly, in the 14 IHC equivocal cases, Q-RT-PCR was highly predictive of the final HER 2 status in 10 out of 13 cases. These results thus validate the use of Q-RT - PCR as alternative to FISH in IHC $2+$ cases. Overall, Q-RT-PCR and IHC had statistically similar efficiency for predicting HER2 status in the overall 466 cases we studied (452 out of 466 and 449 out of 466 , respectively).

Q-RT-PCR is quick, easy to perform, quantitative and has no inter-observer variability. However, dilution of tumour genomic material with non-neoplastic tissue or presence of in situ component are well-known drawbacks of Q-RT-PCR, so that microscopical control of the sample is particularly crucial prior to molecular extraction. If expert pathological selection is performed, microdissection can clearly be avoided (Gjerdrum et al, 2004).

Since Q-RT - PCR can be performed with as little as $100 \mathrm{ng}$ RNA, the corresponding amount of frozen tissue is easily obtained even with $14 \mathrm{G}$ or $16 \mathrm{G}$ fine-needle biopsies of breast tumours (O'Flynn et al, 2010), although a frozen tissue workflow has to be organised. While we determined here the mRNA level using frozen tissues, several reports demonstrated also the good HER2 $\mathrm{mRNA}$ /protein concordance in FFPE samples (Cronin et al, 2004; Barberis et al, 2008).

Immunohistochemistry and Q-RT-PCR are, therefore, two complementary approaches, with an excellent overall sensitivity and with almost no equivocal cases. Measurement of tumour cell percentage and morphological HER2 assessment are done by H\&E and IHC stainings, while quantitative HER2 assessment is obtained by Q-RT - PCR, for moderate costs (Vinatzer et al, 2005). Indeed, the combination of IHC + Q-RT - PCR has an estimated cost of 157.27 euros, compared with 525.68 euros for IHC + FISH determination (Vinatzer et al, 2005). The association of these two techniques in breast cancer would be useful for patient care, each technique controlling and complementing the other one. However, it is not possible to draw similar conclusions in gastroesophageal cancers, now often tested for HER2 status, since these tumours might be more heterogeneous than breast tumours and the use of molecular techniques in this field of pathology should be evaluated.

One rare but significant finding in our study was that a few tumours (12 out of 466) had a highly discordant HER2 status depending on the methods used. One of these discordant cases (tumour \#4) showed chromosome 17 polysomy that is well known to complicate HER2 status analysis (Dal Lago et al, 2006). Another case (tumour \#17) showed highly discordant results among the three antibodies used for IHC, although stainings had been performed on three adjacent tissue sections, maybe reflecting inappropriate fixation of the sample. For the other 10 discordant cases, only hypotheses can be drawn to explain these discrepancies: some of these cases could have a true borderline HER2 status; therefore, being considered negative or positive with only slight technical sensitivity changes.

Intra-tumour heterogeneity may also explain some of these discrepancies, even when the analyses are performed on close tissue areas. We describe here two cases that are typical examples of regional HER2 intra-tumour heterogeneity. In case A, methylation 
Table I Studies comparing Q-RT-PCR and other HER2 assessment methods

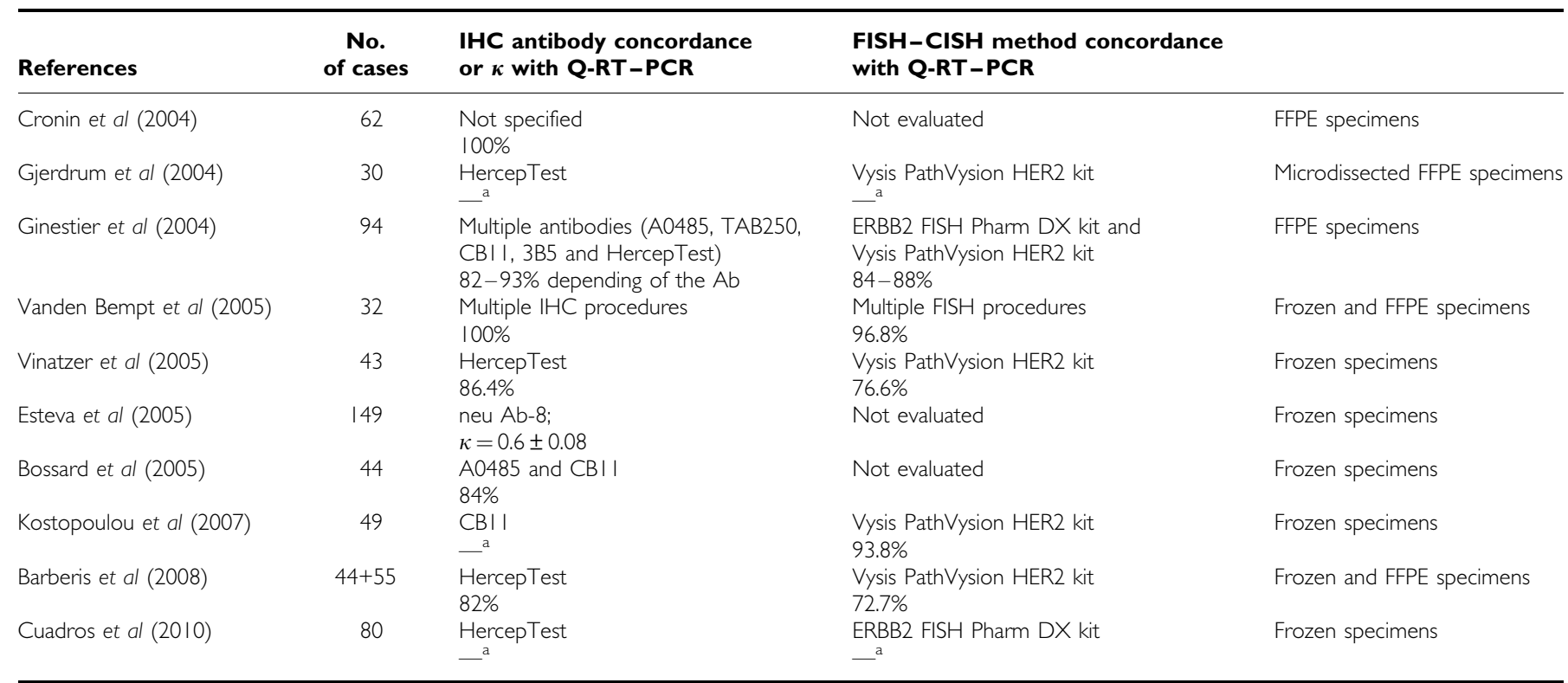

Abbreviations: $\mathrm{CISH}=$ chromogenic in situ hybridisation; FFPE = formalin-fixed paraffin embedded; $\mathrm{FISH}=$ fluorescent in situ hybridisation; $\mathrm{IHC}=$ immunohistochemistry. ${ }^{2}$ These studies used both Q-RT-PCR and one other method, but did not precisely evaluate concordance/discordance between techniques. Note that most studies considered score $2+$ as positive for the calculations, whereas $2+$ cases are very poorly amplified.

of one X chromosome in HER2 + area and methylation of the other $\mathrm{X}$ chromosome in HER2 - area strongly suggest the existence of two distinct tumours, deriving from two distinct initiating tumour cells. Case A would be, therefore, like the so-called 'collision tumours' described by pathologists (Isaka et al, 2007; Kleist et al, 2010) all characterised by the simultaneous occurrence at the same place and at the same time of two tumours with distinct histological types. In case B, the presence in both HER2 + and HER2 - areas of shared new allelic abnormalities strongly suggests that the tumour derives from a single clone, HER2 + area and HER2 - area being two different subclones. Therefore, in case B, HER2 amplification may be a progression event in a clonal tumour cell population, as recently reported (Hanna et al, 2007; Kostopoulou et al, 2007; Cottu et al, 2008; Apple et al, 2009).

In conclusion, we demonstrate an excellent concordance between IHC and Q-RT-PCR for HER2 status assessment in breast tumours. Rare discordances may be due sometimes to intratumour heterogeneity. The association of these two methods in IHC equivocal cases or even in all tumours may be a reliable and moderate-cost strategy for HER2 status assessment. The quantitative nature of Q-RT-PCR could also provide clinically relevant informations, allowing tailored treatment according to the amplitude of HER2 overexpression in breast cancers.

\section{ACKNOWLEDGEMENTS}

We thank all the technicians of St Louis hospital Pathology Department and the technicians of the Biochemistry Department (Catherine Brunin, Dominique Chapelin, Odile Flinois, Laurence

\section{REFERENCES}

Apple SK, Lowe AC, Rao PN, Shintaku IP, Moatamed NA (2009) Comparison of fluorescent in situ hybridization HER-2/neu results on core needle biopsy and excisional biopsy in primary breast cancer. Mod Pathol 22: $1151-1159$

Barberis M, Pellegrini C, Cannone M, Arizzi C, Coggi G, Bosari S (2008) Quantitative PCR and HER2 testing in breast cancer: a technical and cost-effectiveness analysis. Am J Clin Pathol 129: 563-570
Françoise, Brice Geslot, Martine Legrand and Evelyne Wittmer). We also thank Jean Paul Feugeas for statistical advices. This work is dedicated to our friend and colleague Elisabeth Turpin, who initiated this work and who passed away in March 2010 after a long and painful battle against disease. This work was supported by Programme Hospitalier de Recherche Clinique (PHRC), the Association pour la Recherche sur le Cancer (ARC), the Institut National du Cancer (INCa) and the Région Ile de France.

\section{AUTHOR CONTRIBUTIONS}

JL-C and PB have designed the study, performed experiments, analysed the results and written the manuscript. FA-B has performed immunohistochemistry, SISH and microdissection. ET has designed the study and performed Q-RT-PCR experiments. MA and EF have performed and analysed FISH experiments. HS has performed and analysed microsatellite and HUMARA techniques. LL and MV have performed tissue microdissection. $\mathrm{CB}$ has performed Q-RT - PCR experiments. RB has performed immunohistochemical and SISH techniques. AR has analysed IHC experiments and read the manuscript. L-FP has analysed Q-RTPCR results and read the manuscript. SG has collected patients data, analysed results and read the manuscript. ME, CB, LC-D and EB have collected patients data and read the manuscript. AJ has read the manuscript. HT has designed the study, analysed the results and wrote the manuscript.

\section{Conflict of interest}

The authors declare no conflict of interest. , Bjohle J, Borg AL, Skoog L, Bergh J (2007) Quantitative real-time PCR analysis and microarray-based RNA expression of HER2 in relation to outcome. Ann Oncol 18: 845-850

Birner P, Oberhuber G, Stani J, Reithofer C, Samonigg H, Hausmaninger H, Kubista E, Kwasny W, Kandioler-Eckersberger D, Gnant M, Jakesz R (2001) Evaluation of the United States Food and Drug Administration- 
approved scoring and test system of HER-2 protein expression in breast cancer. Clin Cancer Res 7: 1669-1675

Bossard C, Bieche I, Le Doussal V, Lidereau R, Sabourin JC (2005) Real-time RT-PCR: a complementary method to detect HER-2 status in breast carcinoma. Anticancer Res 25: 4679-4683

Cottu PH, Asselah J, Lae M, Pierga JY, Dieras V, Mignot L, Sigal-Zafrani B, Vincent-Salomon A (2008) Intratumoral heterogeneity of HER2/neu expression and its consequences for the management of advanced breast cancer. Ann Oncol 19: 595-597

Cronin M, Pho M, Dutta D, Stephans JC, Shak S, Kiefer MC, Esteban JM, Baker JB (2004) Measurement of gene expression in archival paraffinembedded tissues: development and performance of a 92-gene reverse transcriptase-polymerase chain reaction assay. Am J Pathol 164: 35-42

Cuadros M, Talavera P, Lopez FJ, Garcia-Perez I, Blanco A, Concha A (2010) Real-time RT-PCR analysis for evaluating the Her2/neu status in breast cancer. Pathobiology 77: $38-45$

Dal Lago L, Durbecq V, Desmedt C, Salgado R, Verjat T, Lespagnard L, Ma Y, Veys I, Di Leo A, Sotiriou C, Piccart M, Larsimont D (2006) Correction for chromosome-17 is critical for the determination of true Her-2/neu gene amplification status in breast cancer. Mol Cancer Ther 5: $2572-2579$

Dendukuri N, Khetani K, McIsaac M, Brophy J (2007) Testing for HER2positive breast cancer: a systematic review and cost-effectiveness analysis. CMAJ 176: $1429-1434$

Dietel M, Ellis IO, Hofler H, Kreipe H, Moch H, Dankof A, Kolble K, Kristiansen G (2007) Comparison of automated silver enhanced in situ hybridisation (SISH) and fluorescence ISH (FISH) for the validation of HER2 gene status in breast carcinoma according to the guidelines of the American Society of Clinical Oncology and the College of American Pathologists. Virchows Arch 451: 19-25

Esteva FJ, Sahin AA, Cristofanilli M, Coombes K, Lee SJ, Baker J, Cronin M, Walker M, Watson D, Shak S, Hortobagyi GN (2005) Prognostic role of a multigene reverse transcriptase-PCR assay in patients with nodenegative breast cancer not receiving adjuvant systemic therapy. Clin Cancer Res 11: 3315-3319

Fujita MQ, Hashida N, Shin M, Nakanishi H, Yoshihara W, Aozasa K (1998) Clonal composition of malignant fibrous histiocytoma: analysis by PCR-based assay of the human androgen receptor gene (HUMARA). Oncology 55: 600-606

Ginestier C, Charafe-Jauffret E, Penault-Llorca F, Geneix J, Adelaide J, Chaffanet M, Mozziconacci MJ, Hassoun J, Viens P, Birnbaum D, Jacquemier J (2004) Comparative multi-methodological measurement of ERBB2 status in breast cancer. J Pathol 202: 286-298

Gjerdrum LM, Sorensen BS, Kjeldsen E, Sorensen FB, Nexo E, HamiltonDutoit S (2004) Real-time quantitative PCR of microdissected paraffinembedded breast carcinoma: an alternative method for HER-2/neu analysis. J Mol Diagn 6: $42-51$

Gown AM (2008) Current issues in ER and HER2 testing by IHC in breast cancer. Mod Pathol 21(Suppl 2): S8-S15

Hanna W, Nofech-Mozes S, Kahn HJ (2007) Intratumoral heterogeneity of HER2/neu in breast cancer - a rare event. Breast J 13: 122-129

Isaka T, Nakamura T, Tajika M, Kawai H, Imaoka H, Okamoto Y, Aoki M, Inoue H, Takahashi K, Mizuno N, Sawaki A, Yamao K, Seto M, Yokoi T, Yatabe Y, Nakamura S (2007) API2-MALT1 chimeric transcript-positive gastroduodenal MALT lymphoma with subsequent development of adenocarcinoma as a collision tumour over a clinical course of 7 years. Histopathology 51: 119-123

Isola J, Tanner M, Forsyth A, Cooke TG, Watters AD, Bartlett JM (2004) Interlaboratory comparison of HER-2 oncogene amplification as detected by chromogenic and fluorescence in situ hybridization. Clin Cancer Res 10: $4793-4798$

Kleist B, Lasota J, Miettinen M (2010) Gastrointestinal stromal tumor and gastric adenocarcinoma collision tumors. Hum Pathol 41: 1034-1039

Kostopoulou E, Vageli D, Kaisaridou D, Nakou M, Netsika M, Vladica N, Daponte A, Koukoulis G (2007) Comparative evaluation of noninformative HER-2 immunoreactions (2+) in breast carcinomas with FISH, CISH and QRT-PCR. Breast 16: 615-624

Laakso M, Tanner M, Isola J (2006) Dual-colour chromogenic in situ hybridization for testing of HER-2 oncogene amplification in archival breast tumours. J Pathol 210: $3-9$

Laudadio J, Quigley DI, Tubbs R, Wolff DJ (2007) HER2 testing: a review of detection methodologies and their clinical performance. Expert Rev Mol Diagn 7: $53-64$

Lebeau A, Turzynski A, Braun S, Behrhof W, Fleige B, Schmitt WD, Grob TJ, Burkhardt L, Holzel D, Jackisch C, Thomssen C, Muller V, Untch M (2010)
Reliability of human epidermal growth factor receptor 2 immunohistochemistry in breast core needle biopsies. J Clin Oncol 28: $3264-3270$

Lucas DR, Shroyer KR, McCarthy PJ, Markham NE, Fujita M, Enomoto TE (1997) Desmoid tumor is a clonal cellular proliferation: PCR amplification of HUMARA for analysis of patterns of X-chromosome inactivation. Am J Surg Pathol 21: 306-311

O'Flynn EA, Wilson AR, Michell MJ (2010) Image-guided breast biopsy: state-of-the-art. Clin Radiol 65: 259-270

Owens MA, Horten BC, Da Silva MM (2004) HER2 amplification ratios by fluorescence in situ hybridization and correlation with immunohistochemistry in a cohort of 6556 breast cancer tissues. Clin Breast Cancer 5: $63-69$

Paik S, Bryant J, Tan-Chiu E, Yothers G, Park C, Wickerham DL, Wolmark N (2000) HER2 and choice of adjuvant chemotherapy for invasive breas cancer: National Surgical Adjuvant Breast and Bowel Project Protocol B-15. J Natl Cancer Inst 92: $1991-1998$

Papouchado BG, Myles J, Lloyd RV, Stoler M, Oliveira AM, Downs-Kelly E, Morey A, Bilous M, Nagle R, Prescott N, Wang L, Dragovich L, McElhinny A, Garcia CF, Ranger-Moore J, Free H, Powell W, Loftus M, Pettay J, Gaire F, Roberts C, Dietel M, Roche P, Grogan T, Tubbs R (2010) Silver in situ hybridization (SISH) for determination of HER2 gene status in breast carcinoma: comparison with FISH and assessment of interobserver reproducibility. Am J Surg Pathol 34: 767-776

Pauletti G, Godolphin W, Press MF, Slamon DJ (1996) Detection and quantitation of HER-2/neu gene amplification in human breast cancer archival material using fluorescence in situ hybridization. Oncogene 13: $63-72$

Pritchard KI, Messersmith H, Elavathil L, Trudeau M, O'Malley F, DhesyThind B (2008) HER-2 and topoisomerase II as predictors of response to chemotherapy. J Clin Oncol 26: 736-744

Purdie CA, Jordan LB, McCullough JB, Edwards SL, Cunningham J, Walsh M, Grant A, Pratt N, Thompson AM (2010) HER2 assessment on core biopsy specimens using monoclonal antibody CB11 accurately determines HER2 status in breast carcinoma. Histopathology 56 $702-707$

Sauter G, Lee J, Bartlett JM, Slamon DJ, Press MF (2009) Guidelines for human epidermal growth factor receptor 2 testing: biologic and methodologic considerations. J Clin Oncol 27: 1323-1333

Slamon DJ, Clark GM, Wong SG, Levin WJ, Ullrich A, McGuire WL (1987) Human breast cancer: correlation of relapse and survival with amplification of the HER-2/neu oncogene. Science 235: 177-182

Slamon DJ, Godolphin W, Jones LA, Holt JA, Wong SG, Keith DE, Levin WJ, Stuart SG, Udove J, Ullrich A, Press MF (1989) Studies of the HER-2/neu proto-oncogene in human breast and ovarian cancer. Science 244: $707-712$

Vanden Bempt I, Vanhentenrijk V, Drijkoningen M, Wlodarska I, Vandenberghe P, De Wolf-Peeters C (2005) Real-time reverse transcription-PCR and fluorescence in-situ hybridization are complementary to understand the mechanisms involved in HER-2/neu overexpression in human breast carcinomas. Histopathology 46: 431-441

Varna M, Soliman H, Feugeas JP, Turpin E, Chapelin D, Legres L, Plassa LF, de Roquancourt A, Espie M, Misset JL, Janin A, de The H, Bertheau P (2007) Changes in allelic imbalances in locally advanced breast cancers after chemotherapy. Br J Cancer 97: 1157-1164

Vinatzer U, Dampier B, Streubel B, Pacher M, Seewald MJ, Stratowa C, Kaserer K, Schreiber M (2005) Expression of HER2 and the coamplified genes GRB7 and MLN64 in human breast cancer: quantitative real-time reverse transcription-PCR as a diagnostic alternative to immunohistochemistry and fluorescence in situ hybridization. Clin Cancer Res 11: $8348-8357$

Wang EH, Dai SD, Qi FJ, Hong-Tao X, Wei Q (2007) Gene expression and clonality analysis of the androgen receptor and phosphoglycerate kinase genes in polygonal cells and cuboidal cells in so-called pulmonary sclerosing hemangioma. Mod Pathol 20: $1208-1215$

Wolff AC, Hammond ME, Schwartz JN, Hagerty KL, Allred DC, Cote RJ, Dowsett M, Fitzgibbons PL, Hanna WM, Langer A, McShane LM, Paik S, Pegram MD, Perez EA, Press MF, Rhodes A, Sturgeon C, Taube SE, Tubbs R, Vance GH, van de Vijver M, Wheeler TM, Hayes DF (2007) American Society of Clinical Oncology/College of American Pathologists Guideline recommendations for human epidermal growth factor receptor 2 testing in breast cancer. Arch Pathol Lab Med 131: 18

Yarden Y (2001) Biology of HER2 and its importance in breast cancer Oncology 61(Suppl 2): 1-13 